CATALAN REVIEW

Catalan Review

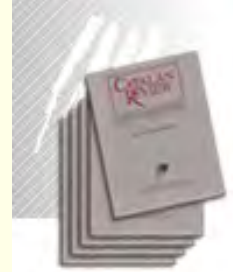

You are accessing the Digital Archive of the Catalan Review Journal.

By accessing and/or using this Digital Archive, you accept and agree to abide by the Terms and Conditions of Use available at http://www.nacs-

catalanstudies.org/catalan review.html

Catalan Review is the premier international scholarly journal devoted to all aspects of Catalan culture. By Catalan culture is understood all manifestations of intellectual and artistic life produced in the Catalan language or in the geographical areas where Catalan is spoken. Catalan Review has been in publication since 1986.
NORTH

AMERICAN

CATALAN

SOCIETY
Esteu accedint a l'Arxiu Digital del Catalan Review

A l' accedir i / o utilitzar aquest Arxiu Digital, vostè accepta i es compromet a complir els termes i condicions d'ús disponibles a http://www.nacs-

catalanstudies.org/catalan review.html

Catalan Review és la primera revista internacional dedicada a tots els aspectes de la cultura catalana. Per la cultura catalana s'entén totes les manifestacions de la vida intel lectual i artística produïda en llengua catalana o en les zones geogràfiques on es parla català. Catalan Review es publica des de 1986.

\title{
Diferències de grau en el canvi lingüístic morfològic dins d'una zona del català i aproximació a les causes Monserrat Adam Aulinas
}

Catalan Review, Vol. XXI, (2007), p. 9-42 


\title{
DIFERENCIES DE GRAU EN EL CANVI LINGÜÍSTIC MORFOLÒGIC DINS D'UNA ZONA DEL CATALÀ I APROXIMACIÓ A LES CAUSES*
}

\author{
MONTSERRAT ADAM AULINAS
}

\section{ABSTRACT}

This paper examines the evolution during the 2oth century of to dialectal features of verbal morphology, in an area of northeastern Catalonia. It compares dialectological data collected by Alcover in the first decades of the $20 t h$ century with data from recent interviews that have been carried out. The general conclusion is that, in this period, whereas features that can be characterized as typical of Roussillon Catalan have receded, those that are typical of Girona Catalan have remained stable in their use or, even, have increased. After presenting the numerical facts, the paper discusses spatialcypology reasons that might explain this particular evolution; it also refers to system-internal reasons that should be taken into account as well.

En aquest treball, ens proposem assenyalar i comentar el canvi lingüístic que han tingut al llarg del segle XX deu característiques de morfologia verbal que es troben a la part nord del català central de manera distintiva respecte a la resta d'aquest dialecte.

\section{Classificació DE LES CARACTERISTIQUES SEGONS LA SEVA TIPOLOGIA ESPACIAL}

Les deu característiques que estudiarem han estat escollides, d'una banda, perquè constitueixen les dues tipologies espacials del nord del català central amb un nombre més elevat de característiques $i$, d'altra banda, perquè hi haurà la possibilitat de comparar el comportament d'aquestes dues tipologies espacials al bisbat de Girona - que ocupa una àmplia zona del nord del català central- atès que és en aquest marc geogràfic on les característiques de tipus II formen intersecció amb les de tipus $I$.

* La redacció d'aquest article s'inscriu dins dels projectes $\mathrm{HUM}_{2004-01504 / F I L O}$ [MEC (Ministerio de Educación y Ciencia) i FEDER (Fondo Europeo de Desarrollo Regional)] i HUM 2005-2821/FILO. 
La classificació basada en la distribució espacial a què ens acabem de referir parteix d'una concepció dinàmica de l'espai similar, en certa manera, a la que proposa la teoria matemàtica de grafs. Així, una característica queda definida per la seva trajectòria o camí que efectua des d'un punt de partida (o zona en què el tret té el grau màxim de realització) fins a un punt d'arribada (o zona en què el tret té el seu grau mínim de realització). Cal remarcar que es tracta d'una visió sincrònica (és a dir, "punt de partida" vol dir simplement allà on el tret té actualment el punt àlgid i no pretén indicar on el tret es va originar des d'un punt de vista diacrònic). ${ }^{1}$

Anomenarem distribució espacial de tipus I la que presenten les característiques que formen àrea de continuitat de manera exclusiva - dins dels límits del català - entre el dialecte rossellonès i la zona nord del català central; aquestes tenen el seu grau màxim de realització al rossellonès $\mathrm{i}$ un nivell inferior a la zona nord del català central contigua. (El tipus I està representat a la fig. I de l'annex mitjançant línies rectes discontínues.)

Qualificarem com a distribució espacial de tipus II la d'aquelles característiques que tenen com a àmbit el bisbat de Girona d'una manera molt aproximada. ${ }^{2}$ (El tipus II està representat a la fig. I amb les línies que formen una xarxa travada.)

Hi ha altres característiques de morfologia verbal al nord del català central que tenen una tipologia espacial diferent de les que acabem d'indicar; aquestes característiques no s'examinaran aquí de manera específica perquè no afecten -0 afecten d'una manera molt tangencial- el bisbat de Girona. ${ }^{3}$ Sí que tractarem, però, d'una característica

' Podem fer esment d'un estudi lingüístic anterior que ha fet ús de la concepció dinàmica de l'espai relacionada amb la teoria matemàtica de grafs: el de Hudlett. L'estudi esmentat, però, a differència del que aquí ens ocupa, no fa referència al marc interdialeotal de la zona estudiada sinó que es limita a assenyalar els punts de màxima i de minima realització del tret dins d'una zona concreta que l'autor ha acotat prèviament. D'altra banda i quant a la la teoria matemàtica de grafs estricta, vegeu per exemple Berge.

${ }^{2}$ El bisbat de Girona comprèn les comarques del Gironès, la Garrotxa, el nord-est del Ripollès -concretament part de la Vall de Camprodon-, l'Alt Empordà, el Baix Empordà, el Pla de l'Estany, la Selva (excepte Sant Hilari Sacalm i Osor) i l'extrem nord del Maresme. (Cal indicar que a la resta del Ripollès també hi han aparegut diversos trets de la tipologia II (= gironina).)

3 Quant a les característiques de morfologia verbal que es localitzaven als inicis del segle $\mathrm{xx}$ també al nord del catala central de manera distintiva respecte a la resta del dialecte i que aquí no s'examinen, tenim les següents: a) Una caracteristica que, igual que les que hem anomenat de tipus II, era autònoma dels dialectes circumdants; aquesta, però, es trobava sols al sector centre de la franja nord del català central - concretament, al Ripollès i

- a l'oest de la Garrotxa (es prolongava, a més, cap al sud-oest). b) Tres altres caracteristiques que formen àrea de continuitat tant amb el rossellonès com amb el català nord-occidental, c) $I$, encara, dues altres característiques que formaven àrea de continuitat amb el català nord-occidental però no amb el rossellonés (vg. Adam, El catalá 294-343). 
que es localitza a tot l'eix horitzontal deI nord del català central -és a dir, des de la comarca de la Cerdanya (aquesta inclosa) fins al mar-, però que té una manifestació de naturalesa específica a la part centre i est (concretament al bisbat de Girona), de manera que, pel que fa a aquest sector, permet de ser analitzada també juntament amb les de tipus II; aquesta és la característica que hem numerat amb el núm. io (vg. \$II), per a la qual presentarem dues anàlisis: l'una, en què s'examina de manera separada de la tipologia II i, l'altra, en què s'avalua de forma conjunta amb les característiques de la tipologia esmentada, ${ }^{4}$ 4

\section{CARACTERISTIQUES LINGÚISTIQUES QUE S'EXAMINARAN}

Presentem aquí la relació de característiques objecte d'estudi: ${ }^{5}$

Car. I: Morf de persona-nombre $=/ \mathrm{i} /$ a la primera persona singular del present d'indicatiu (ex. cantz) [Tipus I].

Car. 2: Morf de mode-temps $=/ \mathrm{a} /(=[0])$ a la segona persona singular del present d'indicatiu en els verbs de les classes II i III (ex. dormes) [Tipus I].

Car. 3: Manca de vocal temàtica a l'infinitiu i vocal temàtica /íl a la resta de temps verbals (ex. fúger fugim) [Tipus I].

Car. 4: Manca d'extensió velar a la primera persona singular del present d'indicatiu del verb 'ser' (som) [Tipus I].

Car. 5: Epítesi [a] a l'infinitiu de verbs monosíl-labs (ex. dire) [Tipus I].

Car. 6: Addició de $/ \mathrm{z} / \mathrm{al} \mathrm{morf} / \mathrm{m} /$ de la primera persona del plural del present d'indicatiu del verb ser (i difusió a altres persones, temps i verbs) (ex. soms) [Tipus II].

Car. 7: Epítesi $[\mathrm{k}] /[\mathrm{t}]$ a la primera persona del singular del present d'indicatiu (ex. càntoc, càntot) [Tipus II].

Car. 8: Epèntesi posterior al morf/ $/ \mathrm{s} / \mathrm{d}$ 'infinitiu (ex. nézx(e)re: né $\mathrm{f}+$ [ə]) [Tipus II].

Car. 9: Final d'arrel lèxica en $/ \mathrm{b} /$ no etimològica per a verbs del subgrup [-w] de la subclasse verbal [II, +ext.] (ex. crevies) [Tipus II].

${ }^{4} \mathrm{Si}$ calgués precisar, a la car. ro (ex. creguem) se li podria assignar un tipus IIb. En aquest cas, la numeració $I /$ es referiria al fet que es tracta d'una característica independent dels dialectes circumdants i la b significaria el seu abast geogràfic concret (lleugerament diferent del de les que hem qualificat com a tipologia II estricta, les quals, si seguissim amb el criteri classificatori indicat, ara caldria qualificar com a Ila).

5 Una descripció lingüústica detallada d'aquestes característiques es troba a Adam (E) catala 87-139, 172-253, 266-93). 
Car. Io: Extensió velar a la primera i la segona persona del plural del present d'indicatiu dels verbs de la subclasse verbal [II, +ext.] (ex. creguem) (sobre el seu tipus espacial, vg. \$ I i nota 4 ).

Des del punt de vista lingüístic, es tracta de: tres característiques relatives a morfs significatius (car. I, 2 i 6); tres característiques que fan referència a morfs de distribució relacionats amb classes o subclasses verbals (car. 3,4 i io); tres característiques relatives a fenòmens d'epèntesi (car. 5,7 i 8 ); i una altra característica que correspon al segment final de l'arrel (car. 9). ${ }^{6}$

D'altra banda, podem observar que quatre d'aquests trets afecten classes verbals (car. I, 2, 7) o subclasses verbals (car. 10); ${ }^{7}$ quatre d'altres, grups més específics de verbs (car. 3, 5, 8 i 9); $i$, dues, el verb ser (car. 4; 6) - la car. 6 s'ha difós també, d'una manera secundària, cap a altres verbs.

\section{DADES EN QUÉ BASEM L'ESTUDI}

Com ja hem indicat a $₫ I$, el fet que les característiques de tipus $\mathrm{I} i \mathrm{de}$ tipus II formin intersecció al bisbat de Girona ens permet comparar el seu comportament en aquest espai. Per a l'estudi que realitzem en l'article present, hem seleccionat les comarques de la meitat nord del bisbat esmentat (comarques de la Garrotxa [= G], l'Alt Empordà [= AE], el Pla de l'Estany [= PE] i el Ripollès $[=\mathrm{R}])^{8}{ }^{8}$

Tenim dades d'aquestes comarques corresponents a dos moments de l'eix temporal: els inicis del segle XX $\mathrm{i}$ el final del mateix segle.

${ }^{6} \mathrm{Pel}$ que fa a la inclusió de trets de tipus fonològic (o fonètic) - i no estrictament morfolögic - cal dir que semblà interessant estudiar les car. 5 (ex. dire) i 8 (ex. nétx (e) ré) per la proximitat dels segments objecte d'estudi al morf d'infinitiu. Quant a la car. 7; el fet que les característiques del tipus cantoc han anat essent substituïdes al llarg del segle Xx per les del tipus cantoc - malgrat que s'ha mantingut la [k] de formes com bec, de la subclasse [II, + ext.] - va fer palès el caràcter merament fonètic a l'àrea examinada del so (i no atribuíble, doncs, a un possible morf [ $\mathrm{k}$ ] de ia. pers. sing. del present d'indicatiu com a voltes havia estat suggerit (vg., sobre aquest punt, Adam, El catala 186-87, "Les formes" 22-25). Cal també indicar que hi ha en catala epítesi $[\mathrm{k}] \mathrm{o}[\mathrm{t}]$ en diversos mots (per exemple, ràvec 'rave', hort 'or' o, fins i tot, tant mart com marc' mar'; vg. Recasens 224-25, 247 i Comas 58 ).

Quant a la car. 9 (ex. crevies) - que fa referència al segment final de l'arrel verbal-, el seu estudi es pot justificar, en un cert sentit, perquè facilita l'enllaç fonològic entre la resta de l'arrel i els morfs flexius, igual com ho fa també el morf corresponent a l'extensió velar (la / b/ final d'arrel de crevem ocupa la posició d'obertura de la sil. laba en què s'apleguen morfs flexius; és aquesta la mateixa posició que ocupa el morf $/ \mathrm{g} /$ de creguem).

-7 Considerem que constitueixen la subclasse verbal [II, + ext.] els verbs de la classe II que duen extensió velar (ex. beure, valer).

"Sobre la inclusió de tota la comarca del Ripollès malgrat que només una part d'aquesta pertanyi al bisbat de Girona, vg, la nota 2. 


\section{III.I Dades dels inicis del segle $\mathrm{xX}$}

Quant a l'anàlisi de la situació dels inicis del segle XX, ens basem en el corpus verbal d'Alcover (1906-28), que inclou les dades que aquest filòleg va recollir arreu del territori de la llengua catalana en el període indicat. Les realitzacions van ser obtingudes, en general, de grups de nens i nenes de deu a catorze anys d'edat que l'autor reunia per fer-los conjugar en veu alta a l'entorn de setanta-cinc verbs. (Tot i que cal assenyalar que, en algunes localitats, s'entrevistaren exclusivament adults, en altres hi hagué com a informants tant infants com adults $i$, en diverses, a les sessions amb els infants hi foren presents també alguns adults que podien haver-hi fet alguna aportació. $)^{9}$ Van ser catorze les localitars de les quatre comarques objecte aquí del nostre estudi que Alcover va enquestar. Les entrevistes s'hi efectuaren el 1906, amb l'excepció de quatre localitats (l'Escala, Camallera [ = municipi de Saus] i Mieres -en les quals es realitzaren el 1918 - iS. Joan de les Abadesses - on es feren el ro21).

\section{2 Dades de final del segle $\mathrm{XX}$}

Pel que fa a la situació lingüística de final del segle xx, disposem de les dades sobre morfologia verbal obtingudes en un treball de camp que vam realitzar els anys 1999-2000 a les quatre comarques esmentades. Les localitats investigades foren vint-i-quatre -les mateixes catorze que enquestà Alcover més deu d'addicionals.

El nombre d'informants per localitat és de tres, i la selecció d'aquests fou feta mitjançant el procediment d'atzar estadístic. Tenien una edat de 50 a 60 anys en el moment de realitzar l'entrevista i havien nascut i vivien a la localitat; era un requisit, d'altra banda, que els seus pares haguessin nascut a la mateixa comarca o en poblacions properes a aquesta., ${ }^{10}$

Ens basarem fonamentalment en les dades corresponents a les res-

${ }^{9}$ Les localitats sense participació infantil o juvenil van ser Mieres (s'entrevistả un eclesiàstic, el qual aleshores residia a Amer - localitat propera a la Garrotxa), Crespià (s'entrevistà un jesuíta que, d'altra banda, residia a Manresa), Rocabruna (s'enquestà el rector de la parròquia) i S. Joan de les Abadesses ( $s^{3}$ enquescaren dos eclesiàstics). Les localitats tant amb informants infants (o joves) com amb informants adults són Maçanet de Cabrenys, Capmany i Olot. A la resta de les localitats aquí estudiades, els informants foren infants (o joves).

10 Resultaren ser 46 dones i 47 homes. Fins al moment la variable "gènere" no ha estat presa en consideració, El fet que tenim només tres informants per localitat determina que aquesta anàlisi no sigui possible per a localitats individuals; no obstant això, sí que es podria investigar fins a quin punt la variable esmentada actua en el mateix sentic a les diverses localitats. 
postes a un qüestionari. Per obtenir aquestes respostes, l'enquestador iniciava una frase que l'informant havia de completar. En aquest estudi sobre el terreny de $1999-2000$, també es mantenia una conversa dirigida amb l'informant al final de l'entrevista $i$, així mateix, es recollien dades de la seva parla espontània; només en algun cas, però, caldrà fer referència aquí a la informació provinent d'aquests altres tipus de discurs.

\section{SOBRE EL PROCEDIMENT DE QUANTIFICACIO I LA REPRESENTACIO DE LES DADES}

\section{I Ítems base de la quantificació. Grau i grau ponderat d'una característica}

Per a cada característica, el qüestionari de la investigació (1999-2000) incloïa preguntes relatives a diversos verbs; així mateix, prenia en consideració diversos temps d'aquells verbs quan s'hi podia manifestar la característica. Si el tret lingüístic podia aparèixer en diverses persones d'un mateix temps verbal, en general s'escollia una o dues persones.

L'estudi complet de les deu característiques va comportar examinar un total de 336 ítems verbals de cada informant (vg. Adam, El catalá 47379). Quant a les quantificacions concretes que aquí es realitzaran, la selecció ha estat de 63 ítems per informant -és a dir, 189 ítems verbals per cada localitat. La raó de la selecció d'ítems efectuada és que, per a la mesura quantificada de cada característica, $s^{\prime}$ ha escollit el temps, la persona o el grup verbal en què la característica es manifestava amb més vigor $^{\text {"I }}$

Un nombre aproximadament similar d'ítems verbals al que hem indicat per a les dades actuals s'utilitzarà aquí per a les dades dels inicis del segle XX -és a dir, aquelles procedents del corpus d'Alcover (rgo628) -, ja que s'ha procurat que els verbs escollits per examinar cada característica coincidissin en la major mesura possible en ambdues

"Concretament, s'han quantificat les dades següents: per a les caracteristiques i i 7, les dades de la primera persona singular del present d'indicatiu dels verbs cantar, menjar, pensar, batre, perdre, rebre, dormir, moni, partir i llegir; per a la car. 2, les dades de la segona persona singular del present d'indicatiu dels verbs batre, perdre, rebre, prometre, dormir i morir; per a la car. 3 , les relatives a l'infinitiu de bullir, collir, cosit, ezixir, fugir, munyit i tenyir, així com les corresponents a la primera persona plural del present $\mathrm{d}^{\prime}$ indicatiu de comer, per a la car. 4 , les dades de la primera persona singular del present d'indicatiu del verb ser, mentre que, per a la car. 6 , les de la primera persona plural del mateix temps i verb; per a la car. 5 , les dades de l'infinitiu dels verbs dir, dur, fer i ser, per a la Car. 8, les dades de l'infinitiu dels verbs aparèxer, conèzxer, créixer, merèixer i néxxer; per a la car. 9, les dades de la segona persona singular de Pimperfet d'indicatiu dels verbs caure, cloure, (com)plaure, coure, creture, jeure, rure, seure i treure, mentre que, per a la car. 10, les de la primera persona plural del present d'indicatiu dels mateixos verbs. 
franges temporals. ${ }^{12}$ Cal puntualitzar, d'altra banda, que el nombre d'informants amb què va comptar Alcover pot variar segons la localitat.

Per obtenir el grau de realització de cada característica, s'han avaluat les respostes corresponents als diversos lexemes verbals que li haviem assignat. Atès que el corpus d'Alcover no especifica quins informants van respondre cadascuna de les realitzacions sinó que indica la realització o les realitzacions alternants - si és el cas- de la localitat, hem fet un càlcul general per a cadascuna d'aquestes. El mateix hem efectuat a l'hora d'analitzar les dades actuals - malgrat que, en aquest cas, teníem el detall de les respostes de cadascun dels tres informants - per tal que la comparació entre ambdós períodes es basés en dades homòlogues.

Per al càlcul general esmentat es va establir que, si almenys un dels informants de la localitat havia respost amb la característica la forma del lexema verbal que es demanava, aquell verb puntuava; la suma corresponent als diversos lexemes $i$ expressada en forma de percentatge és el que anomenem grau d'una característica en una localitat determinada. Per al grau ponderat (segons el factor coexistència), es va determinar que, si almenys un dels informants de la localitat havia respost amb la característica la forma verbal que es demanava $i$, a més a més, algun dels altres informants de la localitat enquestats responia aquella forma verbal sense la característica, el verb puntuava la meitat que per al grau. ${ }^{13}$

Assenyalem que les formes alternants sense la realització de la característica solien ser, en general, les de la varietat més general del català central. ${ }^{\mathrm{I}}$

Les mesures de grau i grau ponderat pretenen donar una idea aproximada de la situació de la característica a les diverses localitats. ${ }^{15}$

"2 El nombre d'ítems verbals per informant del corpus d'Alcover que comptabilitzem és de 58 . La diferència de 5 items respecte als 63 de l'estudi relatiu a les dades actuals (I9992000) es deu, en primer lloc, al fet que, mentre que Alcover per a la classe verbal I només va preveure el verb cantar, el nostre questionari va demanar també els verbs menjari pensar, i, en segon lloc, a la particularitat que, pel que fa al grup dels verbs del tipus nétxer, el corpus d'Alcover no inclou dades del verb créixer.

${ }^{13}$ El valor màxim possible tant del grau d'una característica com del seu grau ponderat és de roo.

14 Per a una excepció d'una certa importància, que farà referència a la car. $10, \mathrm{vg} . \$ \mathrm{~V}_{\mathrm{b}} \mathrm{s}$.

is Indiquem que pretenen donar una idea aproximada de la situació lingüística de la localitat perquè el fet que no basem el recompte en la mitjana dels resultats de cada individu (per la raó assenyalada que no tenim el detall de quina resposta correspon a cadascun dels informants a les dades d'Alcover) fa difícil aplicar-hi tests estadístics estàndards quan es realitzen les comparacions. Cal tenir present, a més, que el nombre d'informants seleccionats de cada localitat per estudiar la seva població estadística - del perfil detallat a \III.2- és tres (un nombre, doncs, en general limitat - feta l'excepció de quan es tracta de localitats amb un nombre molt baix d'informants del perfil requerit). Aixi, doncs, creiem que els nostres resultats permeten traçar les línies més importants de la realitat lingüistica dialectal però no extreure conclusions de diferències molt ajustades. 


\section{IV.2 Pes i pes ponderat d'una tipologia espacial en una localitat}

La suma del graus de realització en una localitat de les caracterîstiques pertanyents a una de les tipologies espacials establertes a $\$$ I és el pes d'aquella tipologia a la localitat assenyalada; i la suma del grau ponderat de realització d'aquelles característiques és el pes ponderat de la tipologia a la localitat. Aquests valors es mostren a la columna i (dades sense ponderar dels inicis del s. XX), a la columna 2 (dades ponderades dels inicis del segle $\mathrm{XX}$ ), a la columna 3 (dades sense ponderar actuals) i a la columna 4 (dades ponderades actuals) dels mapes de les fig. 2,3 i 6 de l'annex; són aquests els valors que prenem com a base per a l'anàlisi que realitzem a $\ \mathrm{~V}$ relativa a l'evolució a cada localitat del conjunt de trets de tipus I respecte a la del conjunt de trets de tipus II.

D'altra banda indiquem que, atès que les característiques de tipus I (rossellonès) es trobaven a l'àrea estudiada en un nombre màxim de cinc, el pes màxim de les característiques d'aquesta tipologia espacial és de 500 . I, pel que fa a les característiques de tipus II (gironí), el seu pes màxim és de $400-$ hi ha quatre característiques de tipus II estricte. Si sumem a aquest darrer tipus II la característica to (vg. $\$$ I, on es justifica la idoneitat d'aquesta possible addició), aleshores el pes màxim en aquest segon grup també seria 500.

Cal també fer observar que la comparació entre el valor de la columna I i el de la columna 2 ens informa sobre la proporció de verbs en què hi havia als inicis del segle XX les variants alternants a què hem fet referència a $\$ I V .1$. El mateix es pot dir de la diferència entre les columnes 3 i 4 pel que fa a les dades de final del segle XX.

Remarquem que, mentre que el grau s'expressa en percentatge, el pes - tant en el cas del pes d'una tipologia espacial en una localitat (que hem definit en aquest $\$ I V .2$ ) com en el del pes d'una característica en un conjunt de localitats (que comentem en el següent $\$ I V .3$ ) - és un nombre absolut (per tal com és una suma de percentatges).

\section{IV.3 Pes i pes ponderat d'una característica en un conjunt de localitats}

Les mesures de pes i de pes ponderat d'una característica en un conjunt de localitats ens serviran per comparar les característiques entre si (cosa que efectuarem a \$ VI). Es tracta de la suma del grau (o percentatge) de realització d'una característica concreta en el conjunt de les catorze localitats amb dades tant dels inicis del segle XX com de finals - "del mateix segle (per al detall d'aquestes localitats, vg. \$IV.4); segons si se sumen els percentatges sense ponderar o els ponderats tindrem els resultats del pes o del pes ponderat. En ser catorze les localitats indi- 
cades i tractar-se de la suma del grau de realització de la característica de cada localitat (amb un valor màxim, aquest darrer, de 100), el valor màxim possible del pes -o el del pes ponderat - serà de 1400 .

\section{IV.4 Relació de poblacions}

Indiquem aquí en nota la relació de les poblacions que es localitzen als mapes de les fig. 2 a 6 així com la seva numeració. ${ }^{16}$ Hi ha un total de vint-i-quatre poblacions $i$, com acabem d'avançar a $\ I V .3$, catorze amb dades tant dels inicis com del final del segle XX. Quan s'assenyala un sol número en una població, es tracta d'una localitat que no enquestà Alcover però que ha estat entrevistada actualment; quan, en canvi, hi ha dos números es tracta d'una localitat que tant enquestà Alcover com ho hem fet actualment - en aquest cas, el primer d'aquests correspon a la numeració de la investigació actual (1999-2000) i el que es troba entre parèntesis correspon a la numeració en el corpus d'Alcover (1906-28).

\section{COMPARACIÓ DE L'EVOLUCIÓ AL LLARG DEL SEGLE XX DEL CONJUNT DE LES CARACTERISTIQUES DE TIPUS I RESPECTE AL CONJUNT DE LES DE TIPUS II}

En aquest apartat analitzarem l'evolució al llarg del segle Xx del conjunt de característiques de tipus I respecte a la que ha tingut el conjunt de característiques de tipus II durant el mateix període. Prendrem com a base per a la comparació les mesures de pes i de pes ponderat d'aquestes dues tipologies espacials a cadascuna de les localitats (vg. $\$$ IV.2). El mapa de la fig. 2 correspon a les dades de les cinc característiques de tipus I; el de la fig. 3, a les quatre de tipus II estricte; els mapes de les fig. 4 is de l'annex es destinen a mostrar el grau de realització d'inicis i de final de segle respectivament de la característica núm. 1o; i al mapa de la fig. 6 trobem reunides les dades corresponents a les quatre característiques de tipus II estricte més les de la característica io.

${ }^{16}$ [Ripollès = R]: 8 (24) Ripoll; 9 Gombrèn; 10 (22) Ribes de Freser; II (23) S. Joan de les Abadesses; 12 (21) Camprodon; 13 (19) Rocabruna (municipi: Camprodon); 14 Espinavell (municipi: Molló). [Garrotxa = G]: 15 (25) Olot; 16 S. Joan les Fonts; 17 Oix (municipi: Montagut); 18 Tortellà; 19 Besalú; 20 S. Esteve d'en Bas (municipi: Vall d'en Bas); 21 (3I) Mieres. [Alt Empordà = AE]: 22 (27) Figueres; 23 Llers; 24 (16) Maçanet de Cabrenys; 25 (17) Capmany; 26 Llançà; 27 (20) Cadaqués; 28 (32) L'Escala; 29 (30) Saus - Camallera Llampaies (municipi: Saus). [Pla de l'Estany = PE]: 30 Banyoles; $3 \mathrm{I}$ (29) Crespià. 


\section{V.I Característiques del tipus I (= rossellonès)}

\section{V.I. I Inicis del segle $X X$}

Distribució dins de l'ärea. Pel que $\mathrm{fa}$ als inicis del segle XX i fent atenció al que hem anomenat pes de les característiques d'una tipologia en una localitat determinada, la manifestació més important de les característiques de tipus I (rossellonès) en la zona de les comarques examinades era al seu sector nord (vg. la primera columna de la fig. 2 ) - de manera congruent amb el que el seu tipus espacial permetia esperar.

Canvi lingü̈stic des de la sincronia. Si examinem el pes ponderat (vg. la segona columna de la fig. 2), podem adonar-nos, a partir de la comparació entre aquest valor $\mathrm{i}$ el de la columna i, que la presència de formes alternants era manifesta - hem indicat a \$IV.I que, en general, aquestes formes alternants són les de la varietat més general del català central.17

\section{V.1,2 Final del segle $x x$}

Canvi lingüüstic des de la diacronia. Confrontarem ara els resultats actuals del mateix tipus I amb els corresponents dels inicis del segle XX. Amb aquesta finalitat, examinarem la tercera i la quarta columnes -les quals mostren, respectivament, el pes i el pes ponderat actuals de les característiques de tipus rossellonès - $\mathrm{i}$ compararem els seus valors amb els de la primera i la segona columnes - que es refereixen als valors corresponents, però dels inicis del segle $\mathrm{XX}^{18}$

A partir de la comparació esmentada, es pot observar com els trets de tipus I (rossellonès) presos en conjunt han disminuït d'una manera molt important en el transcurs del segle XX a les diverses localitats (cal exceptuar-ne Cadaqués, on aquesta pèrdua ha estat més moderada). ${ }^{19}$

\footnotetext{
17 Efectivament, el valor de la columna 2 ès, en general, molt inferior al de la columna I (amb l'excepció de Cadaqués i, en menor mesura, de Maçanet de Cabrenys). El contrast entre pes sense ponderar i pes ponderat és especialment rellevant al Ripolless, ja que hi ha valors alts del conjunt de trets de tipus $\mathrm{I} i$, alhora, uns valors a la columna 2 que són sovint la meitat dels anteriors, cosa que ens indica que les formes amb la característica coexistien pràcticament en tots els casos amb les de la varietat més general del català central.

${ }^{18} \mathrm{La}$ comparació diacrònica només pot realitzar-se, evidentment, per a les catorze localitats amb dades d'ambdós períodes (vg. $\ I V, 4)$. Les dades actuals de la resta de localitats poden ajudar a tenir una visió més àmplia de la realitat de la zona.

- 19 El comportament diferenciat de Cadaqués tant per als trets de tipus I -que acabem d'indicar - com per als trets de tipus II (vg, \$V.2.2) podria explicar-se per la seva comunicació poc fàcil per terra amb la resta del bisbat de Girona tins fa poc temps i pel seu 'enllaç marítim possible amb els ports del Rosselló.
} 


\section{V.2 Característiques del tipus II (= gironí)}

V.2 I Inicis del segle $x x$

Distribució dins de l'àrea. Si es comparen les dades dels inicis del segle XX de les característiques de tipus II (= gironí) - vg. les columnes primera i segona de la fig. 3- amb les del mateix període corresponents al tipus I (= rossellonès) - que s'han presentat a la fig. 2 , en les columnes primera i segona-, podem apreciar com el conjunt de les característiques de tipus II es trobava, a bona part de les quatre comarques examinades, amb un nivell de realització més important que el del conjunt de les de tipus rossellonès -només en alguns punts del nord de l'Alt Empordà predominava aquest darrer; al Ripollès el pes d'ambdós tipus de característiques estava força igualat.

(Cal tenir en compte que el valor màxim expressat a la llegenda de tots els mapes és de soo per tal de facilitar la comparació entre els diversos mapes. No obstant això, per als trets de tipus gironí que examinem a la fig. 3 el màxim que podria trobar-se en qualsevol localitat seria sols de $400(\mathrm{vg} . \$(\mathrm{IV} .2)$.)

Canvi lingüüstic des de la sincronia. Comparant el valor del pes sense ponderar $i$ el del pes ponderat del tipus II dels inicis del s. XX -vg, les columnes primera i segona de la fig. 3 , respectivament-podem apreciar que, si una forma verbal presentava la característica en una població determinada, en general no hi havia o bé hi havia en pocs casos la forma alternant pròpia de la varietat del català central més comú. (Al Ripollès aquesta coexistència era més important, tot i que no tant com en el cas de les característiques de tipus $\mathrm{I}$. $)^{20}$

\section{V.2.2 Final del segle $X X$}

Canvi lingüstic des de la diacronia. A partir de la mateixa fig. 3 es pot avaluar el canvi lingüistic esdevingut durant el segle $\mathrm{xX}$ per al conjunt de les quatre característiques de tipus II aquí examinades. Si comparem les dades d'Alcover (col. $\mathrm{t}$ i 2 , on hi ha el pes sense ponderar $\mathrm{i}$ el pes ponderat respectivament) amb les dades actuals (col. 3 i 4 , també corresponents al pes $\mathrm{i}$ al pes ponderat), podem adonar-nos com encara actualment $i$ pel que fa, almenys, al segment poblacional examinat, hi ha uns percentatges molt importants de les característiques de tipus gironí.

${ }^{20} \mathrm{La}$ poca diferència entre els valors de les columnes $\mathrm{r}$ i 2 és el que ens assenyala que hi havia pocs verbs que presentaven l'alternança. 
Fixant-nos només en les localitats per a les quals disposem de dades d'ambdós períodes - que són, per tant, aquelles en què trobem quatre columnes-, es detecta en diverses un augment en la realització del conjunt de trets de tipus gironí aquí examinats; ${ }^{21}$ en algunes altres s'observa una disminució de les característiques de tipus gironí, però en uns nivells lleus respecte al que, a partir del mapa de la fig. 2 , hem vist que s'havia esdevingut per a les característiques de tipus rossellonès -hi ha només l'excepció del sud del Ripollès, on la disminució dels trets de tipus gironí ha estat remarcable; el sector esmentat tenia ja uns percentatges baixos d'aquest tipus de trets als inicis del segle XX $i$ actualment hi són pràcticament imperceptibles. ${ }^{22}$ (D'altra banda, Cadaqués presenta l'especificitat que tenia als inicis del s. XX un valor baix del conjunt d'aquest tipus de trets i encara l'hi tindria actualment - per a una explicació sobre el comportament diferenciat de Cadaqués, vg. la nota 19.)

\section{V.3 La característica to (ex. creguem): anàlisi individual i anàlisi conjunta amb les de tipus II}

\section{V.3.1 Anàlisi individual de la caracteristica to}

Realitzarem, en primer $1 l o c$, una anàlisi individual de la característica to (ex. creguem). Tot i que ja hem assenyalat a I I que, pel que fa a la seva tipologia espacial, es podria, de fet, ajuntar a les de tipus II (cosa que realitzarem a $\$$ V.3.2), creiem que pot ser útil analitzar-la també de manera aillada perquè la interpretació dels seus valors ponderats no és tan simple com per a la resta; s'esdevé que, per a les altres característiques, les formes que alternen amb les que presenten la característica són, en general, les de la varietat més comuna del català central; per a la característica 1o, en canvi, la coexistència apareix d'una manera clara tant amb les formes d'aquesta darrera varietat com amb una altra classe de formes (sobre les quals vg. \$V.3.I.I).

${ }^{21}$ Aquest augment es fa palès a l'est de la Garrotxa, al Pla de l'Estany i a l'Alt Empordà (amb l'excepció de Cadaqués - vg. infira al text principal). L'augment del tipus II en les zones indicades es deu, bàsicament, a la difusió de la característica 6 -corresponent a la realizzació soms $4 \mathrm{PI}$ 'ser' en comptes de som. (A Maçanet de Cabrenys, s'hi ha d'afegir la substítució de la car. 1 (ex. canti) per la car. 7 (ex. cántoc/cántot).)

${ }^{22} \mathrm{Cal}$ indicar que, pel que $\mathrm{fa}$ a les quatre comarques examinades, és el sud del Ripollès el sector en què, al llarg dél segle xx, Pàrea ha entrat en contacte més directe amb la varietat més general del català central; les altres tres comarques tenen la protecció de les

- comarques de la meitar sud del bisbar de Girona, ja que són aquestes darreres les que termenegen amb la varietat més general del català central. Podem també assenyalar que els contactes entre les comarques de la Garrotxa i d'Osona (aquesta darrera es troba par- cialment al sud d'aquella, però té ja bisbat propi) són més aviat escassos per raons orogràfiques i històriques. 
Al mapa de la fig. 4 trobem el grau de realització de cadascuna de les variants alternants als inicis del segle XX; $i$, a la fig. 5 , hi ha la informació corresponent a les dades de final del segle.

\section{V.3.I.I Inicis del segle $\mathrm{xx}$}

Distribució dins de l'àrea. Si ens limitem a les quatre comarques aquí analitzades, podem assenyalar que la característica ro (ex. creguem) es localitzava als inicis del segle XX bàsicament a dues d'aquestes comarques: el Ripollès i l'Alt Empordà (vg. fig. 4). És interessant d'assenyalar que la comarca intermèdia (la Garrotxa) pràcticament no la presentava. Aquesta distribució s'adiu amb la nostra hipòtesi que el tret hauria sorgit pel contacte amb el català central més general. ${ }^{23}$

Canvi lingüistic des de la sincronia. Als inicis del s. Xx hi havia coexistència de les formes que presenten la característica amb unes altres que hem interpretat com a genuïnes de la zona (ex. crevem) - vg. nota 23-, així com amb les del català central més general.

\section{V.3.r.2. Final del segle $\mathrm{xx}$}

Canvi lingüustic des de la diacronia. Actualment la característica to (ex. creguem) s'ha expandit cap a la comarca en què era pràcticament inexistent als inicis del segle XX (la Garrotxa) - vg. fig. 5. Ha augmentat la seva presència a l'Alt Empordà. Al Ripollès es manté en uns nivells de coexistència amb les altres variants força similars als dels inicis del segle $x x .^{24}$

${ }^{23}$ Considerem que estem davant de la substitució de les formes del tipus crevem (que tenen o haurien tingut com a àmbit el bisbat de Girona) per les del tipus creguem. Al català central més general no hi ha crevem (hi ha creiem); la diversitat de solucions de la varietat més general del català central per a aquests verbs (ex. coem, creiem, bevem) podia haver dificultat l'adopció del seu sistema lingüistic en aquest punt. El fet que, al subjuntiu, ambdues varietats lingüístiques (la del català central més general i la de la zona que examinem) coincidien en el tipus cregnem podria haver facilitat l'adopció d'aquestes formes al present d'indicatiu -vg. Adam ("L'extensión $\{6$, El catala 269-71). Així, doncs, la substitució de les formes del tipus crevem per les del tipus cregwem representaria, en definitiva, l'intercanvi d'una forma dialectal per una altra també dialectal però menys marcada geolingüisticament que l'anterior. (Podem indicar, addicionalment, que les formes del tipus crevem són la manifestació a les persones primera i segona del plural del present d'indicatiu de la característica , - la qual en aquest article hem avaluat només per a l'imperfer d'indicatiu [ex. crevies] perquè és aquest el temps en el qual el nivell de realització de la característica era més important.)

${ }^{24}$ El fet que Alcover només entrevistés una localitat a la comarca del Pla de l'Estany - ens referim a Crespià - i només un informant d'aquesta, el qual era un jesuita que vivia aleshores a Manresa (vg. nota 9), no ens permet precisar si no hi havia en aquells moments la caracteristica a la comarca o si, més probablement, hi apareixia en un cert nivell. 
V.3.2 Anàlisi conjunta de les característiques de tipus II $i$ de la núm. Io

A la fig. $6 \mathrm{~s}$ 'han aplegat les dades de les característiques 6 a 10. Les conclusions a què es pot arribar a partir dels resultats que allà se'ns mostra són molt semblants a les que hem exposat a partir de l'anàlisi de les car. 6 a 9 efectuada a $\$$ V.2 (fig. 3). Hi ha sols la diferència que, atès que la característica to ha anat en augment al llarg del segle xx, en alguna població per a la qual l'anàlisi diacrònica dels trets de tipus II estricte indicava una pèrdua lleugera dels trets, ara hi tenim un lleuger augment. ${ }^{25}$

\section{DESCRIPCIÓ DELS RESULTATS \\ DE CADASCUNA DE LES CARACTERISTIQUUES}

Detallem aquí els resultats de cadascuna de les característiques per examinar si el seu comportament s'allunya del que hem descrit a $\$ \mathrm{~V}-\mathrm{el}$ qual havíem determinat prenent en consideració el resultat de totes les característiques de la tipologia juntes.

\section{VI.I Variació del pes de les característiques}

A la taula I (pàgina següent) s'assenyala el pes i el pes ponderat de cada característica als inicis del segle $\mathrm{XX}$ i al final d'aquest en el conjunt de les catorze poblacions de la meitat nord del bisbat de Girona per a les quals téníem dades d'ambdós períodes - vg. a \$IV.3 la descripció d'aquesta mesura. ${ }^{26}$

${ }^{25}$ Deixem de banda la particularitat que a la fig. 6 tenim uns valors de pes i de pes ponderat més alts que els de la fig. 3 per a totes les columnes en general per tal com hi hem sumat el grau de realització d’una altra característica.

${ }^{26}$ Fem observar que, per a dues característiques, la taula r indica un valor igual a 0 . Si $s^{\prime}$ 'escaigués que s'hagués arribat a aquest valor nul abans de 1999-2000, tindriem que el canvi lingüistic hauria estat, per a aquestes caracteristiques, encara més ràpid que el que la taula esmentada permet deduir. 
TAULA I

PES DE CADASCUNA DE LES CARACTERISTIQUES EN EL CONJUNT DE LES CATORZE POBLACIONS DE LA MEITAT NORD DE LA DIÓCESI DE GIRONA DE LES QUALS TENIM DADES TANT DELS INICIS COM DEL FINAL DEL $S X X$

(VALOR MAXIM: I400)

\begin{tabular}{|c|c|c|c|c|c|c|}
\hline \multirow[b]{2}{*}{$\hat{3}$} & \multicolumn{2}{|c|}{$\begin{array}{c}\text { Dades Alcover } \\
\text { (1906-1928) }\end{array}$} & \multicolumn{2}{|c|}{$\begin{array}{l}\text { Dades actuals } \\
(1999-2000)\end{array}$} & \multicolumn{2}{|c|}{$\begin{array}{l}\text { Canvi lingüístic } \\
\text { en valors absoluts }\end{array}$} \\
\hline & $\begin{array}{l}\text { Pes sense } \\
\text { ponderar }\end{array}$ & $\begin{array}{l}\text { Pes } \\
\text { ponderat }\end{array}$ & $\begin{array}{l}\text { Pes sense } \\
\text { ponderar }\end{array}$ & $\begin{array}{l}\text { Pes } \\
\text { ponderat }\end{array}$ & $\begin{array}{l}\text { Variació } \\
\text { del pes sense } \\
\text { ponderar }\end{array}$ & $\begin{array}{l}\text { Variació } \\
\text { del pes } \\
\text { ponderat }\end{array}$ \\
\hline $\begin{array}{l}\text { Car. I } \\
\text { (ex. cantt) }\end{array}$ & 900 & 535,72 & 100 & 90 & -800 & $-445,72$ \\
\hline $\begin{array}{l}\text { Car. } 2 \\
\text { (ex. dormes) }\end{array}$ & 976,67 & 558,33 & 633,33 & 425 & $-343,34$ & $-133,33$ \\
\hline $\begin{array}{l}\text { Car. } 3 \\
\text { (ex. friger) }\end{array}$ & 254,77 & 217,85 & 185,71 & 128,57 & $-69,06$ & $-89,28$ \\
\hline $\begin{array}{l}\text { Car. } 4 \\
(\mathrm{som})^{\text {s.t }}\end{array}$ & noo & 700 & 0 & 0 & -1100 & -700 \\
\hline $\begin{array}{l}\text { Car. } 5 \\
(\text { ex. dire })^{\text {*h }}\end{array}$ & 50 & 50 & 0 & a & -50 & -50 \\
\hline $\begin{array}{l}\text { Car. } 6 \\
\text { (ex. soms) }\end{array}$ & 600 & 450 & 1100 & 900 & +500 & +450 \\
\hline $\begin{array}{l}\text { Car. } 7 \\
\text { (ex. cäntoclcantot }\end{array}$ & c) 728,57 & 542,86 & 550 & 300 & $-178,57$ & $-242,86$ \\
\hline $\begin{array}{l}\text { Car. } 8 \\
\text { (ex. néix(e)re) }\end{array}$ & 1058,33 & 979,17 & 1020 & 740 & $-38,33$ & $-239,17$ \\
\hline $\begin{array}{l}\text { Car. } 9 \\
\text { (ex. crevies) }\end{array}$ & 1137,5 & 1037,5 & II 96,43 & 1045,14 & $+58,93$ & $+7,64$ \\
\hline $\begin{array}{l}\text { Car. Io } \\
\text { (ex. creguem) }\end{array}$ & 400 & 218,75 & 677,18 & 427,48 & $+277,18$ & $+208,73$ \\
\hline
\end{tabular}

* El signe "-" indica pèrdua de pes de la característica i el signe “+" indica guany (en el valor que s'indica).

*: Cal prendre en consideració la possibilitat que s'hagués arribat al valor o abans de la data 1999-2000 (vg. nota 26).

De l'anàlisi de la variació dels pesos esmentats, es desprenen les gradacions assenyalades a $\mathbb{\text { VI.I.I }}$ - per a les dades sense ponderar - i a $\$$ VI.I.2 - per a les dades ponderades.

Indiquem que l'ordre de la gradació és de més a menys pèrdua per a les característiques els resultats de les quals ens assenyalen pèr- 
dua de pes (xifres negatives); i és de menys a més guany per a les característiques amb resultats que indiquen guany de pes (xifres positives).

\section{VI.I.I Dades sense ponderar}

Desglossem les dades de variació del pes sense ponderar de cada característica segons que es tracti de pèrdua o de guany d'aquest en el conjunt de les catorze localitats amb dades tant dels inicis com del final del s. $\mathrm{xx}$ examinades. El valor màxim del pes és de $I_{400}\left(=I_{4}\right.$ localitats $\mathrm{x} 100 \%$ de grau de realització màxim possible a cada localitat $-\mathrm{vg}$. $\ \mathrm{IV}_{3}$ ) .

Pèrdua: car. 4 (som) $[-$ Iroo $]>$ car. I (ex. cantt) $[-800]>$ car. 2 (ex. dormes) $[-343,34]>$ car. 7 (ex. cantocl cantot) $[-178,57]>$ car. 3 (ex. fúger) $[-69,06]>$ car. 5 (ex. dire) $[-50]>$ car. 8 (ex. néux (e) re $)[-38,33]$.

Guany: car. 9 (ex. crevies) $[+58,93]<$ car. Io (ex. creguem) $[+277,18]$ $<$ car. $6($ soms $)[+500] .{ }^{27}$

Interpretació dels resultats. Per a la interpretació dels resultats, cal tenir present el que ha estat exposat a \$IV.r i, més específicament, a la nota is, en el sentit que, atès el tipus de dades de què disposem, serà lícit de remarcar les diferències quantitatives importants però no podrem concedir importància excessiva a diferències poc notables.

Amb la condició indicada, realitzem seguidament l'anàlisi de la variació del pes sense ponderar de les diverses característiques a partir de les dades donades a l'inici d'aquest \$ VI.1.r:

a) Les diverses característiques de tipus I

Per a totes les característiques de tipus espacial I (rossellonès), els resultats indiquen pèrdua de pes. No totes han tingut una pèrdua de nivell similar; destaquen, pel que fa a minva, la car. 4 (som) i, seguidament, la car. I (ex. cantz) - totes dues amb pèrdues de més de la meitat del pes màxim que una característica hauria pogut tenir.

b) Les diverses característiques de tipus II

$\mathrm{Cal}$ que indiquem que, en l'anălisi d'aquest apartat, hi incloem també la característica io (ja hem comentat a \$ I la possibilitat de considerar també de tipus II aquesta característica). Les remarques que es poden fer sobre les diverses característiques de tipus II (gironí) són les següents:

${ }^{27}$ Indiquem, addicionalment, el percentatge que correspon al valor de la pèrdua o el guany de cada caracteristica respecte al valor que aquella tenia als inicis del segle XX: car. 4 (som) $[-100 \%]$; car. I (ex. canti) $[-88,89 \%]$; car. 2 (ex. dormes) $[-35,15 \%]$; car. 7 (ex. " cantoc/cantot) $[-24,51 \%]$; car. 3 (ex. figger) $[-27,11 \%]$; car. 5 (ex. dive) $[-100 \%]$; car. 8 (ex. néxx(e)re) $[-3,62 \%]$.

Guany: car. 9 (ex. crevies) $[+5,18 \%]$; car. to (ex. creguem) $[+69,30 \%]$; car. 6 (ex. soms) $[+83,33 \%]$. 
bi) Totes les característiques per a les quals els resultats obtinguts assenyalen guany pertanyen al tipus espacial II.

b2) $\mathrm{Hi}$ ha un augment notable de dues característiques d'aquest tipus II: la car. 6 (ex. soms) i la car. to (ex. creguem). L'augment de la car. Io (ex. creguem) es podria justificar si tenim present el que ha estat indicat a la nota 23 , en el sentit que, en darrer terme, l'aparició d'aquesta característica seria un acostament a la varietat més general del català central. L'augment de la car. 6 (ex. soms) podria semblar més sorprenent; però, si les dades d'Alcover (1906-28) fossin fidels a la realitat del seu temps, tindríem que aquesta característica, reduida aleshores fonamentalment al Ripollès i a l'oest de la Garrotxa, s'hauria estès cap a l'est al llarg del segle XX. ${ }^{28}$

b3) El petit guany de la car. 9 (ex. crevies) i la petita pèrdua de pes de la car. 8 (ex. néix (e)re) es podrien considerar, o bé uns valors inclosos dins de l'interval de dispersió del que en realitat seria absència d'increment o de minva, o bé uns valors atribuibles a petites diferències en la metodologia de realització de l'enquesta - aquestes diferències no s'han fet presents, en general, a l'estudi, però en algun punt concret $i$ amb uns valors baixos podrien haver existit. ${ }^{29}$

b4) Cal comentar, finalment, la minva de realització de la car. 7 (cantoc/cantot). Considerem que hi ha la possibilitat que la reducció esmentada es degui al fet que, dins del qüestionari, la posició prevista per al mot que calia respondre era davant de pausa. Efectivament, l'anàlisi de la conversa dirigida (que, com hem indicat a \$III.2, també formava part de l'entrevista) ens va assenyalar que, si la forma verbal precedia un mot començat per vocal, la realització era molt més freqüent. De totes maneres, cal reconèixer que, mitjançant el mètode de fer recitar verbs d'Alcover, tampoc la forma verbal es devia trobar, en general, abans de vocal. Es fa difícill, però, amb les dades de què disposem, precisar més sobre el comportament d'aquesta característica pel que fa al canvi lingüístic al llarg del segle XX.

${ }^{28}$ Des del punt de vista lingüistic, hem interpretat aquesta característica com a addició d'una $/ \mathrm{z} /$ al morf de persona-nombre de la ra pers. plural del verb ser; element que pot haver estat adoptat de la morfologia nominal amb la finalitat de destruir el sincretisme som (ra pers. sing.) / som (ra pers. plu.) que es trobava a la zona als inicis del segle XX (vg. Adam, El catala 172-73).

${ }^{29} \mathrm{Hi}$ afegim que el percentatge sobre el pes inicial de pèrdua o d'augment d'aquestes característiques 8 ig és molt petit (veg, nota 27). I, encara i pel que fa a la car. 9 (ex. crevies), cal dir que considerem molt difícil des del punt de vista lingüistic i sociolingüistic que un informant o els seus descendents hagin realiczat el camí invers de P'esperat, és a dir, hagin tornat a les solucions del tipus crevies (car.9) després d'haver adoptat les solucions del tipus creies del català central més general. 


\section{VI.I.2 Dades ponderades}

Presentem aquí les dades que es corresponen amb les de \$VI.I.I, però en els seus valors ponderats segons el factor "coexistència".

Pèrdua: car. 4 (som) $[-700]>$ car. I (ex. cantz) $[-445,72]>$ car. 7 (ex. càntoc/càntot) $[-242,86]>$ car. 8 (ex. néux (e) re $)[-239,17]>$ car. 2 (ex. dormes) $[-133,33]>$ car. 3 (ex. fúger) $[-89,28]>$ car. 5 (ex. dire) $[-50]$.

Guany: car. 9 (ex. crevies) $[+7,64]<$ car. 1o (ex. creguem) $[+208,73]$ $<$ car. 6 (ex. soms) $[+450]$.

Interpretació dels resultats. Si comparem els resultats de les dades ponderades amb els de les dades sense ponderar (indicades a $\$$ VI.I.I), ens adonem que hi ha poques diferències pel que fa a la gradació de les característiques. La diferència bàsica és que, mentre que per a la car. 8 (ex. néix(e)re), hi hauria hagut un possible manteniment a les dades sense ponderar (o, si es volgués, una pèrdua dèbil), a les dades ponderades hi ha una minva manifesta..$^{30}$ Això significa que, mentre que encara trobaríem actualment les formes dels diversos lexemes verbals amb la realització de la característica 8 (ex. néxx(e)re) com als inicis del segle XX, hi haurien començat a aparèixer, en coexistència, les formes de la varietat més general del català central. Per poder donar aquesta interpretació com a definitiva, hi ha el problema que, mentre realitzàvem les entrevistes, ens adonàrem que, a voltes, si el mot es pronunciava amb una intensitat baixa, la $[r]$ no se sentia; de manera que hi ha l'interrogant de si els casos consignats sense $/ \mathrm{r} /$ ho eren efectivament 0 bé són realitzacions de / $/$ fonològica però imperceptible a l'oïda a causa de l'emissió amb poca intensitat de veu. Caldria, doncs, una ampliació de l'estudi que pogués determinar en quin dels dos supòsits ens trobem.

\section{VI.I.3 Resum de §VI.I}

Així, després de les consideracions de $₫$ VI.1.1 i \$ VI.1.2, es pot concloure que totes les característiques de tipus I haurien disminuit - per bé que amb diferents nivells: car. 4 (som) $>$ car. I (ex. cantz) $>$ car. 2 (ex. dormes) $>$ car. 3 (ex. füger) $>$ car. 5 (ex. dive).

Si ens referim ara a les de tipus II - hi incloem la car. to (ex. creguem) -, es pot concretar que algunes haurien augmentat (car. 6 [soms]

${ }^{30}$ Una altra diferència, més secundària, és una posició més baixa de la car. 7 (ex. càntoo(cantor) dins l'escala respecte a la que hi renia en les dades sense ponderar. Ja hem indicat a \$VI.I, però, que per concretar més sobre la variació major o menor d’aquesta caracteristica all llarg del s. Xx hi ha el problema de la interferència del context fonolögic en la seva realizzació. 
i Io [ex. creguem]) i d'altres s'haurien mantingut (car. 9 [ex. crevies] i dades sense ponderar de la car. 8 [ex. nézx(e)re]).

Resta comentar, en aquest apartat de resum, d'una banda la car. 7 (ex. càntoc/càntot), per a la qual el context fonològic davant de pausa de les respostes que el qüestionari corresponent a les dades actuals havia previst podria haver determinat els resultats només mitjans de realització d'aquesta característica - encara que tampoc no es pot descartar una pèrdua al llarg del segle Xx del grau de realització de la característica en el context fonològic esmentat (vg. \$ VI.r.I b4); i d'altra banda, la car. 8 (ex. néix(e)re), sobre la qual s'ha d'indicar que caldria una ampliació de l'estudi per poder interpretar el nivell inferior de les seves dades ponderades respecte al que tenien als inicis del segle XX (hi ha la possibilitat que, si més no en alguns casos, ens trobem davant d'una dificultat de percepció quan el mot es pronunciava amb una intensitat baixa i no -o no tant - de l'aparició de variants alternants provinents del català central més comú).

\section{VI.2 Confrontació de la variació del pes de les característiques a la corba-S del canvi lingüístic de Chen}

Hem volgut prendre en consideració una particularitat que podria fer variar la gradacions indicades a \$VI.1.1 - ens limitarem a analitzar les dades sense ponderar. Segons Chen, en els primers estadis temporals del canvi lingüístic aquest afecta poques realitzacions; en els estadis mitjans, hi ha un increment important en un període de temps breu del nombre de realitzacions que mostren el canvi lingüístic; $i$, en els estadis finals, el nombre de realitzacions guanyades per a la característica torna a ser baix. L'autor utilitza una corba en forma de S (la corba-S) per presentar gràficament l'observació esmentada.

Per examinar si la funció representada per la corba-S podria alterar la gradació de característiques que hem presentat a \& VI.I.I, hem partit per a cadascuna dels seus graus de realització final i inicial -representats a l'eix Y - (la resta aritmètica dels quals ens dóna la variació del pes que aquella característica ha tingut al llarg del segle Xx) i hem projectat els seus valors a l'eix X (corresponent al temps transcorregut per al canvi que s'analitzi) després de la intermediació de la funció representada per la corba-S que hem traçat. ${ }^{31}$ Restant els valors corresponents de l'eix $\mathrm{X}$, obtenim el nombre de períodes de la corba del canvi

3. Vam preveure realitzar els càlculs a partir de la representació gràfica de la corba. Per facilitar Poperació $i$ atès que el màxim de pes per a cada característica era de 1400 (vg. \ IV.3), hem traçat una corba-S que s'encabís en un quadrat, de manera que s'ha donat una puntuació màxima de 14 periodes a l'eix de les $\mathrm{X}$. 
lingüístic d'una característica determinada (d'un total de I4, per convenció - vg. nota 3I) que aquesta hauria recorregut al llarg del segle $\mathrm{XX}$. La gradació de les característiques que es farà present a partir del nombre de períodes que cadascuna haurà recorregut ja estarà lliure del possible biaix atribuible al major o menor pes inicial de cada característica (ja que l'aplicació de la corba-S ha permès eliminar el biaix). $\mathrm{Cal}$ precisar, d'altra banda, que aquesta corba - que hem fet encabir en un quadrat (vg. nota 3I) - s'ha de considerar com una idealització de la corba-S perquè, en realitat, aquesta podria dibuixar-se més o menys allargassada. ${ }^{2}$

A la fig. 7 de l'annex hi ha la corba-S assenyalada, així com un exemple il.lustratiu del tipus de correspondència que permet establir entre la variació de la realització de la característica quan no es pren en consideració el que es descriu a Chen i quan es pren en consideració que el canvi lingüístic té un ritme o un altre segons de quin estadi del procés es tracti (en el primer cas, estem parlant dels valors representats a l'eix $\mathrm{Y}$ i, en el segon cas, dels valors representats a l'eix X).

A la taula 2 hi ha l'especificació dels valors corresponents al canvi de pes de les característiques però en la seva projecció a l'eix temporal de les X.

TAULA 2

Perfodes ReCORREgutS D'UNA CORBA-S DEL CANVI LiNGÜÍSTIC IDEALITZADA (NOMBRE MAXIM DE PERÍODES: I4).*

\begin{tabular}{lr}
\hline & Dades sense ponderar \\
\hline Car. I (ex. cantz) & $-3,8 \mathrm{I}$ \\
Car. 2 (ex. dormes) & $-\mathrm{I}, \mathrm{I}$ \\
Car. 3 (ex. fúger) & $-0,44$ \\
Car. 4 (som) & $-8,34$ \\
Car. 5 (ex. dire) & $-2,6$ \\
Car. 6 (ex. soms) & $+\mathrm{I}, 67$ \\
Car. 7 (ex. cäntoc/càntot) & $-0,47$ \\
Car. 8 (ex. néix(e)re) & $-0,13$ \\
Car. 9 (ex. crevies) & $+0,42$ \\
Car. 10 (ex. creguem) & $+0,93$ \\
\hline
\end{tabular}

* El signe "-" significa pèrdua de la característica i el signe "+", guany (en el nombre de períodes que s'indica).

$32 \mathrm{I}$, doncs, els resultats a partir d'aquestes altres corbes podrien mostrar certes diferències respecte als que aquí presentem. 
La gradació que es pot obtenir a partir de la taula 2 esmentada coincideix amb la que hem presentat a $\$$ VI.I.I - elaborada, en aquell cas, a partir dels resultats de la taula $\mathrm{I}$ - excepte en un punt: es tracta de la car. 5 (ex. dire), el canvi lingüístic de la qual pren ara més relleu i passa a ocupar la posició tercera pel que fa a la importància de la seva disminució lingüística (i se situa, doncs, després de les característiques $4(\mathrm{som})$ i i (ex. cantz)). Això significa que, encara que la pèrdua del pes de la característica s hagi estat petita, en realitat la minva té més significació perquè s'ha escaigut en el darrers períodes temporals del canvi lingüiştic (que és un dels moments en què aquest va més lent).

Així, a la interpretació que hem fet a $\int$ VI.I.3 dels resultats de totes les característiques (i a $\S$ VI.I.I, de manera més especifica, de les seves dades sense ponderar) caldria, des de la nova perspectiva d'anàlisi aquí presentada, incorporar-hi només el canvi de posició de la car. 5 (ex. dire) esmentat. ${ }^{33}$

\section{APROXIMACIÓ A LES CAUSES DEL DIFERENT COMPORTAMENT DE LES CARACTERISTIQUES}

\section{I Raons de tipologia espacial}

Hem vist a $\$ V$ com, a la zona estudiada - que ha estat la meitat nord del bisbat de Girona-, el comportament al llarg del segle XX del conjunt de les característiques de tipus espacial I (és a dir, aquelles que tenen la realització màxima al rossellonès) ha estat més recessiu que el del conjunt de les de tipus espacial II (és a dir, el d'aquelles que tenen com a àmbit aproximat el bisbat de Girona). I, més concretament, a diferència del que s'ha esdevingut per a les característiques de tipus I, en diverses localitats hi ha hagut per al tipus II pres en conjunt un augment del seu pes de realització (hi incloem també la característica 1o).

D'altra banda, hem constatat a $\$$ VI que el comportament diferenciat del tipus I respecte al tipus II també es confirma, en general, si examinem les característiques individualment. ( $\mathrm{Hi}$ podria haver dues excepcions al que acabem d'assenyalar: la car. 7 (ex. càntod cantot) i les dades ponderades de la car. 8 (ex. néxx(e)re); però, com allà hem indicat, caldria investigar més a fons aquests dos casos).

Malgrat la correspondència que acabem de constatar, cal demanarse si la raó del comportament diferent dels dos tipus de característiques és, precisament, la seva pertinença a una o altra tipologia espacial.

33 Especifiquem que incorporem aquí implicitament les consideracions que hem fet a $\$$ VI.r.I i a \VI.I.3 sobre la resta dels resultats de la taula $1 ;$ i, doncs, interpretem adequada per al que aquí analitzem la gradació allà fixada excepre en allò que fa referència a la car. 5 . 
Hi ha raons de tipus geomètric per pensar que és així: una xarxa de punts com la de les característiques de tipus I ha de ser més vulnerable a la pressió del català central més general que una xarxa de punts de tipus II (vg. fig. 8 i fig. 9 de l'annex, respectivament). Cal aquí precisar que la varietat més general del català central s'ha anat introduint a la zona especialment des dels sectors geogràfics del sud contigus al bisbat esmentat que tenen com a pròpia la varietat més general del català central (tot i que és també cert que el fet que la varietat més general del català central coincideixi amb l'estàndard o bé que en diferents punts de la zona sigui present el turisme provinent de Barcelona ha ocasionat que hi pugui haver hagut també pressió en alguns altres punts).

La major vulnerabilitat esmentada de les característiques de tipus I es basaria en el fet que, en aquest cas, el focus de realització màxima de la característica es troba a l'àrea catalana d'un altre estat polític (França) $i$, al sud dels Pirineus, la realització de la característica va disminuint progressivament. En el cas del tipus espacial II, el focus esmentat es troba dins del mateix bisbat de Girona.

Volem remarcar també que les xarxes de les tipologies espacials lingüístiques assenyalades revelen, en realitat, camins de relacions humanes que han fet possible que, en diferents sectors geogràfics, hi hagi una mateixa característica lingüística. En aquest sentit, es podria afirmar que els contactes humans que la xarxa de tipus II representa semblen haver tingut al llarg del segle XX més importància que els que mostra la xarxa de tipus I.34

A la possible importància de la localització del focus principal de realització de les característiques - en un altre estat o bé dins del bisbat de Girona, segons la tipologia espacial a la qual pertanyen-, hi afegirem que, en general, les característiques de tipus II tenien als inicis del segle XX una distribució més àmplia per tota l'àrea del bisbat esmentat que no pas les de tipus I. Efectivament, tenim característiques de tipus II que aleshores pesentaven una distribució àmplia a tota l'àrea del bisbat de Girona -car. 7 (ex. càntoclcàntot), car. 8 (ex. néix(e)re) i car. 9 (ex. crevies) - i tenim característiques de tipus I que als inicis del segle XX hi tenien una distribució petita - car. 5 (ex. dire) - o bé mit-

\footnotetext{
${ }^{34} \mathrm{Si}$ es volgués, en aquest punt es podria introduir la reflexió sobre si hi podria haver tingut també importància el fet de la poca vitalitat del català a la Catalunya Nord. S'esdevé que, per a les persones nascudes a partir de 1950 aproximadament, la llengua que els pares catalans els han transmès ha estat el francès (Verdaguer 86). És a dir, es tractaria d'un contacte poc sovintejat entre ambdues bandes de la frontera política $i$, encara, amb una varietat rossellonesa amb molt poca vitalitat. Caldria un estudi per aprofundir en aquest punt. De totes maneres, sí que podem apuntar que no hem trobat cap ús remarcable de gal-licismes en les comarques investigades al sud de la frontera estatal pel que fa a la generació r nascuda en el període 1939-49 - que és la que ha estat objecte de la nostra anàlisi-, cosa que semblaria corroborar la importància que hem concedit al factor que fa referència al contacte poc intens entre ambdues bandes de la frontera esmentada.
} 
jana - car. I (ex. cantz), car. 3 (ex. fúger), car. 2 (ex. dormes). Podríem considerar, d'altra banda, que la car. 1o (ex. creguem) ocupava també, virtualment, bona part el bisbat de Girona: si en alguns sectors no s'hi trobava és perquè encara no hi havia substituït les formes del tipus crevem; però la presència d'aquestes darreres formes així com els factors a què abans ens hem referit - vg. $\$$ V.3.1.r i la nota 23 - propiciaven que la nova característica s'hi pogués desenvolupar.

$\mathrm{Cal}$, no obstant això, indicar que hi ha dues característiques per a les quals no hi ha la possible correspondència entre tipologia espacial i major o menor extensió del tret dins de l'àrea que acabem d'esmentar. La primera d'aquestes és la car. 6 (ex. soms): segons les dades d'Alcover (1906-28), aquesta característica de tipus II ocupava als inicis del segle XX només un sector del bisbat de Girona. ${ }^{35}$ La segona característica que es desmarca de les de la seva tipologia pel que fa a la distribució dins del bisbat de Girona és la car. 4 (som, corresponent a la ra persona singular del present d'indicatiu del verb ser); efectivament, la característica esmentada, de tipus I, es trobava distribuïda als inicis del s. XX a bona part del bisbat de Girona, per bé que cal dir que, en moltes localitats, ja presentava coexistència amb la forma més general del català central sóc..$^{36}$

Malgrat, però, que hi hagi raons de tipus geomètric per pensar en una major resistència del tipus espacial II a la pèrdua dels trets que no pas el tipus espacial I - les quals hem exposat-, per poder certificar des d'un punt de vista quantitatiu la importància de la tipologia espacial en el desenvolupament del canvi lingüístic hi ha el problema que les característiques d'una tipologia i de l'altra no són homòlogues des del punt de vista lingüístic: ni pel que fa a la naturalesa lingüística de les característiques ni pel que fa a la seva major o menor dificultat de substitució.

Efectivament i limitant-nos a la naturalesa lingüística de les característiques, podem observar que, mentre que en els trets de tipus rossellonès objecte d'estudi trobem dos morfs significatius (car. I [ex. cantz] i car. 2 [ex. dormes]), dos morfs de distribució - el primer dels

${ }^{35} \mathrm{Aixi}$, doncs, quant als factors que, des d'un punt de vista de la tipologia espacial, serien favorables per al manteniment d'aquesta característica, tindriem el fet que el nucli màxim de realització d'aquesta es trobava dins del bisbat de Girona, peró no, en canvi, l'existència d'una distribució generalitzada per tota l'àrea.

${ }^{36}$ La raó de la distribució àmplia d'aquesta característica malgrat pertànyer al tipus I és que la forma som (de la ra pers. sing. del present d'indicatiu del verb ser) havia estat anterioment la pròpia també de la resta del català, per tal com és el resultat primer de l'evolució de la llatina SUM. Als inicis del segle XX aquesta forma som de la primera persona singular havia anat reculant del català central i quedava només en el seu sector nord, de manera que venia a formar, de fet, continuitat amb la forma corresponent sense extensió velar del rossellonès. (Podem afegir-hi que al balear es pot trobar també encara som per a aquesta mateixa forma de ta pers. sing. del present d'indicatiu.) 
quals fa referència a la classe verbal (car. 3, ex. füger) i, l'altre, a l'absència d'extensió velar (car. 4 , som) -, així com una epèntesi fonètica - concretament una epitesi (car. 5, ex. dire) -, en els trets de tipus gironí trobem un morf significatiu (car, 6, ex. soms), dues epèntesis - la de la car. 7 (ex. cantoc o càntot), que és concretament una epítesi, i la de la car. 8 (ex. néix(e)re)-, un segment final d'arrel verbal (car. 9, ex. crevies) i un morf de distribució - que és la presència d'extensió velar (car. Io, ex. creguem).

\section{VII.2 Raons lingüístiques}

A l'apartat anterior hem exposat raons de tipologia espacial de les característiques que podrien explicar el seu comportament diferenciat. No obstant això $i$ atès que, com hem assenyalat, la diversitat de la naturalesa lingüística d'aquestes ens impedeix arribar a conclusions definitives sobre el paper de la tipologia espacial en el canvi linguístic, considerem que cal deixar constància que hi ha algunes raons de naturalesa lingüística estricta que podrien explicar també el comportament de determinades característiques. Ens limitem en aquest article a apuntar-les; són les que a continuació es detalla.

a) Cal referir-se, en primer lloc, a la importància de la difusió de l'extensió velar en la morfologia verbal del català des de l'edat medieval. Aquesta particularitat s'ha manifestat en la car. $4($ som $\rightarrow$ sóc) i en la car. Io (crevem $\rightarrow$ creguem).

b) La dificultat fonètica d'efectuar el canvi lingüistic de la forma genuïna de l'àrea per la de la varietat més general del català central podria explicar la resistència al canvi de les formes del tipus crevies (car. 9); és difícil aquest canvi en el cas d'alguns verbs-com pot ser el que aquí ens serveix d'exemple-perquè al català central més general hi ha una forma rizotònica (ex. creies).

c) Ens centrem aquí en les raons relacionades amb el que anomenem "morfologia natural".

cI) Exposem, primerament, els comentaris relatius als principis de la morfologia natural independents del sistema (els d'iconicitat, d'uniformitat i de transparència). Aquests permetrien justificar dues característiques. Es tracta de la car. 4 (som $\rightarrow$ sóc) - a la qual, d'altra banda, ens hem referit també al punt a precedent - i de la car. 6 (som $\rightarrow$ soms), corresponents a les persones primera del singular i primera del plural, respectivament, del present d'indicatiu del verb ser.

El principi d'iconicitat - el qual afavoreix les construc- 
cions morfològiques en què es marca formalment el que està marcat morfosintàcticament - podria haver ajudat a l'aparició de la car. 6 (som $\rightarrow$ soms) ja que la categoria de plural queda expressada mitjançant un morfema independent dels altres. (Cal assenyalar, en contrapartida, que inicialment aquest pas hauria vulnerat el principi de congruència del sistema - pertanyent al grup de principis que s'analitzen a $c 2$ - per tal com no hi havia aquesta $s$ en la resta de verbs; la difusió ulterior d'aquest tret cap a altres verbs que $s^{\prime}$ ha constatat en alguns sectors geogràfics podria explicar-se com un intent de reparar el problema esmentat.)

Pel que $\mathrm{fa}$ als principis d'uniformitat i de transparència -relacionats amb l'universal de Humboldt i que deixen constància de la tendència que existeixi una relació biunívoca entre la forma de les unitats lingüístiques i la seva funció-, aquests podrien haver actuat tant en el cas de la car. 4 (som $\rightarrow$ sóc - canvi corresponent a la primera persona del singular) com en el cas de la car. 6 (som $\rightarrow$ soms - en aquesta cas, el canvi fa referència a la primera persona del plural). El fet és que, als inicis del s. XX, la forma som servia tant per a la primera persona del singular del present d'indicatiu com per a la primera persona del plural. Amb la substitució per sóc (car. 4) o per soms (car. 6), obtenim formalment una distinció entre singular i plural en comptes del sincretisme inicial. ${ }^{37}$

c2) Aplegarem aquí els comentaris relacionats amb els principis de la morfologia natural dependents del sistema. Si ens referim a la car. 4 , al que ja ha estat exposat a l'apartat a podem afegir que l'element velar $/ g /(=[k])$ que apareix a la ra pers. sing. del present d'indicatiu és coincident amb el que es troba en els verbs de la subclasse [II, +ext.] del català, de manera que el fet que existia prèviament aquesta particularitat paradigmàtica en una classe verbal constituïda o estable podria haver afavorit l'aparició de l'element velar per al verb irregular ser; ens trobaríem, en aquest cas, davant del principi de l'estabilitat de les classes flexives, que hauria propiciat aquí la substitució d'un tret corresponent a un verb irregular per un altre comú als verbs d'una subclasse verbal.

D'altra banda, podem assenyalar que el principi de congruència del sistema podria haver afavorit, per a la car. 9 (ex. crevies), el manteniment de les formes $\mathrm{amb} / \mathrm{b} /$ final d'arrel -les

${ }^{37}$ En mots de Wheeler ("Sincretismo" 45I), sincretisme és el fet de no distingir en algun punt - o el procés d'esborrar parcialment - l'expressió formal de categories gramaticals que una llengua segueix mantenint vives en altres punts del sistema. 
quals hem considerat genuïnes de la nostra zona. Efectivament, la subclasse [II, +ext.] té un nivell més alt de congruència a l'àrea del bisbat de Girona que al català central més general: a la zona examinada, per a tots els verbs de la subclasse esmentada hi ha /b/ final d'arrel a l'imperfet d'indicatiu i hi tenim formes arizotòniques; en el cas de la varietat més general del català central, hi ha diversitat de solucions (ex. creia, coila, bevia).

El mateix principi de congruència del sistema podria haver actuat a favor de l'augment de la car. to (ex. creguem), per tal com a les classes verbals regulars del català central les persones esmentades coincideixen també en els dos modes indicats. (Cal fer notar, en contrapartida, que els principis de la morfologia natural independents del sistema no ajuden a explicar-la: si ens referim als principis d'uniformitat i de transparència, s'escau que ens trobem davant un canvi lingüistic que anul-la la distinció categorial de mode (indicatiu vs, subjuntiu) per a dues persones - la primera i la segona plural del present-; $i$, pel que fa al principi d'iconicitat, incorpora una marca (la velar /g/) a una categoria no marcada, com és l'indicatiu. (Vg. Adam, El catalá 267; Wheeler, "Changing" 181, 184, 189, 196.)

(Pel que fa al conjunt de principis de naturalitat morfològica independents del sistema, vg. Mayerthaler (48-52); KilaniSchoch (97-IOI) i Pérez Saldanya $(22-24)$. I, pel que fa als principis de naturalitat morfològica dependents del sistema, vg. Wurzel (59-87); Kilani-Schoch (IOI-II) i Pérez Saldanya (24-27).)

Cóm a resum d'aquest $\$$ VII.2, assenyalem que, del total de les deu característiques examinades, almenys per a dues (car. 4 i g) hem trobat raons de tipus estrictament lingüístic que permetrien també explicar el seu comportament amb relació al manteniment o al canvi lingüístic. Per a dues altres (car. 6 i io), hem indicat raons tant per a l'aparició de la característica com perquè aquesta no hagués fet acte de presència.

\section{CONCLUSIONS}

Hem realitzat l'anàlisi comparada del canvi lingüistic que han tingut al llarg del segle XX les característiques pertanyents a dues tipologies espacials diferents que formen intersecció al nord del català central $i$, més concretament, al bisbat de Girona: les de tipus I o rossellonès (que són les que tenen el nivell màxim de realització a la Catalunya Nord) i les de tipus II o gironí (amb els nivells màxims dins del mateix bisbat de Girona). Ens hem cenyit aquí a l'anàlisi de les comarques de la meitat nord del bisbat esmentat. 
Si ens referim a les característiques de tipus I o rossellonès considerades en conjunt, s'observa al territori estudiat que, als inicis del segle XX, apareixien ja amb una certa freqüència juntament amb les formes verbals que presentaven el tret lingüístic aquelles corresponents a la varietat més general del català central - amb la qual la zona termeneja al sud-, de manera que el procés de substitució lingüística ja havia començat per a aquest tipus de trets. La comparació diacrònica amb les dades actuals ens assenyala que hi ha hagut al llarg del segle XX una disminució important del tipus de característiques esmentat.

Qtant a les característiques de tipus II o gironí considerades en conjunt, generalment no hi havia als inicis del segle XX signes de substitució lingüística (se n'exceptuaria, bàsicament, el Ripollès, on les formes del català central hi eren més manifestes). Pel que fa als canvis esdevinguts al llarg del segle, trobem augment d'aquest tipus II de trets en alguns poblacions; en altres hi ha hagut disminució però en un grau inferior respecte al que s'hi observa per a les característiques de tipus I.

L'anàlisi individual de cada característica - fonamentada en la suma de les dades de les diferents localitats amb informació d'ambdós períodes estudiats-no s'allunya excessivament del que hem descrit per al conjunt de la seva tipologia. Efectivament, totes les caracteristiques de tipus I han disminuit $i$, quant a les característiques de tipus II, dues han augmentat, una s'ha mantingut $i$, en el cas d'una quarta, si fem atenció a les dades sense ponderar també s'hauria mantingut. Pel que $\mathrm{fa}$ a les dades ponderades d'aquesta darrera característica - que és la car. 8 (ex. néix (e)re) -, així com per a una cinquena - es tracta de la car. 7 (ex. càntod cantot)-, caldria un estudi complementari que pogués determinar amb més exactitud si hi ha hagut o no disminució: caldria saber, per a la car. 8, si estem exclusivament davant de problemes de percepció auditiva quan el mot era pronunciat amb una intensitat baixa; $i$, per a la car. 7 , fins a quin punt el context fonològic posterior pot haver interferit en els resultats.

Quant als motius sobre el diferent comportament de les característiques, hem exposat algunes raons geomètriques que indiquen que la xarxa de punts que permet representar a l'espai les característiques de tipus I ha de ser, pel que fa al bisbat de Girona, menys resistent al canvi lingüístic que la xarxa corresponent a les característiques de tipus II. Atès, però, que la diversitat de la naturalesa lingüística de les característiques no permet arribar a conclusions definitives basades en la comparació quantificada, hem apuntat algunes raons de tipus estrictament lingüístic que també es podria prendre en consideració per a una anàlisi àmplia dels factors que poden haver intervingut en el canvi lingüístic. 


\section{REFERÈNCIES}

ADAm AUlinas, Montserrat. "L'extensió velar a les persones 4, 5 del present d'indicatiu al nord-est del català central”. Journal of Catalan Studies (2004). 20 maig 2008 <http://www.uoc.edu/jocs/ 7/articles/adam/index.html>.

-. El català septentrional de transició: nova visió des de la morfologia. Barcelona: Institut d'Estudis Catalans, 2006.

-. "Les formes de la primera persona del present d'indicatiu cantoc i càntot”. Actes del Tretzè Col-loqui Internacional de Llengua i Literatura Catalanes. Ed. S. Martí et al. Vol. 2. Barcelona: Abadia de Montserrat, 2007. 7-28.

Alcover, Antoni M. [Corpus de flexió verbal, 1906-28. Ed. F. de B. Moll, I929-32; ed. M. P. Perea, 1999.]

Berge, Claude. Théorie des graphes et ses applications. París: Dunod, 1958.

Chen, Matthew. "The Time Dimension: Contribution toward a Theory of Sound Change". Foundations of Language 8 (1972): 457-98.

Comas Caussa, Josep. "Caracterització del parlar de Pau (Alt Empordà)”. Tesi de llicenciatura. U de Barcelona, 1970.

HudletT, Albert. Morphologie verbale dans les parlers du Pays de Bitche (Moselle germanophone). Essai de représentation graphique automatique de la dynamique des variations géolinguistiques. Berna: Peter Lang, 1989.

KILANI-SCHOCH, Marianne. Introduction à la morphologie naturelle. Berna: Peter Lang, 1988.

MAYERTHALER, Willi (I987). "System-Independent Morphological Naturalness". Leitmotifs in Natural Morphology. Ed. Wolfgang U. Dressler. Amsterdam: Benjamins, 1987. 25-58.

MOLL, Francesc de B. "La flexió verbal en els dialectes catalans". Anuari de l'Oficina Romànica de Lingüistica i Literatura. Vol. II (I929): 73-I84 [I-II2]; vol. III (I930): 73-I68 [I-96]; vol. IV (I93I): 9-IO4 [I-96]; vol. V (I932): 9-72 [I-64]. Barcelona.

Perea, M. Pilar. Compleció $i$ ordenació de La flexió verbal en els dialectes catalans d'A. M. Alcover i F. de B. Moll. Barcelona: Institut d'Estudis Catalans, I999.

Pérez Saldanya, Manuel. Del llatí al català. Morfosintaxi verbal bistòrica. València: U. de València, 1998.

ReCASENS I VIVES, Daniel. Fonètica descriptiva del català. (Assaig de caracterització de la pronuncia del vocalisme i consonantisme del català al segle XX.) Barcelona: Institut d'Estudis Catalans, I99I.

Verdaguer, Pere. Qui sem/són els catalans del nord. Perpinyà: Associació Arrels, 1992.

WHEELER, Max W. "Sincretismo entre categorías modales y cambio 
desinencial en el verbo románico". Actes du XVIIème Congrès International de Linguistique et Philologie Romanes, Aix-en-ProvenCe, 1983. Vol. 2. Aix-en-Provence: U de Provence, 1985. 449-60.

- . "Changing Inflection: Verbs in North West Catalan". Hispanic Linguistic Studies in Honour of F. W. Hodcroft. Ed. David Mackenzie i Ian Michael, Llangrannog: Dolphin, 1993. 171-206.

WURZEL, Wolfgang U. "System-Dependent Morphological Naturalness in Inflection". Leitmotifs in Natural Morphology. Ed. Wolfgang U. Dressler, Amsterdam: Benjamins, 1987. 59-96. 


\section{ANNEX}

Fig. 1 Morfologia verbal al nord del català central; tipologies espacials I i II

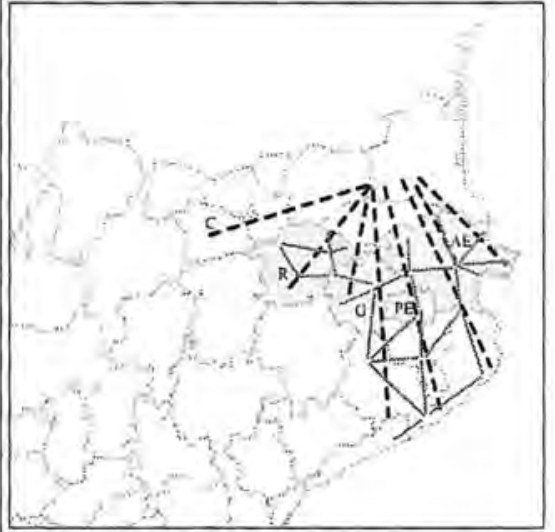

Conarques per a les quals es comparm els tipers I i I

R: Ripollés; O: Garrobxa; AE: Alt Empordz; PE: Pla de IEstany; C: Cerdanya.

Fig. 2 /

Tipus 1

Car. I tricani

Car, 2 exidarmes

Cat, 3 ex.: finger - Jugint

Car. 4 ex. wout (1 Pl 'ser')

Car, 5 ex: dive

Pes $=500$
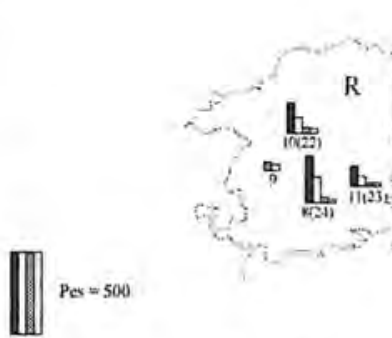

Pes Pesponderat

Dades Alcover (1906-1928)

Dades 1999-2000

Comparació Dades Alcover (1906-1928)

i Dades 1999-2000 


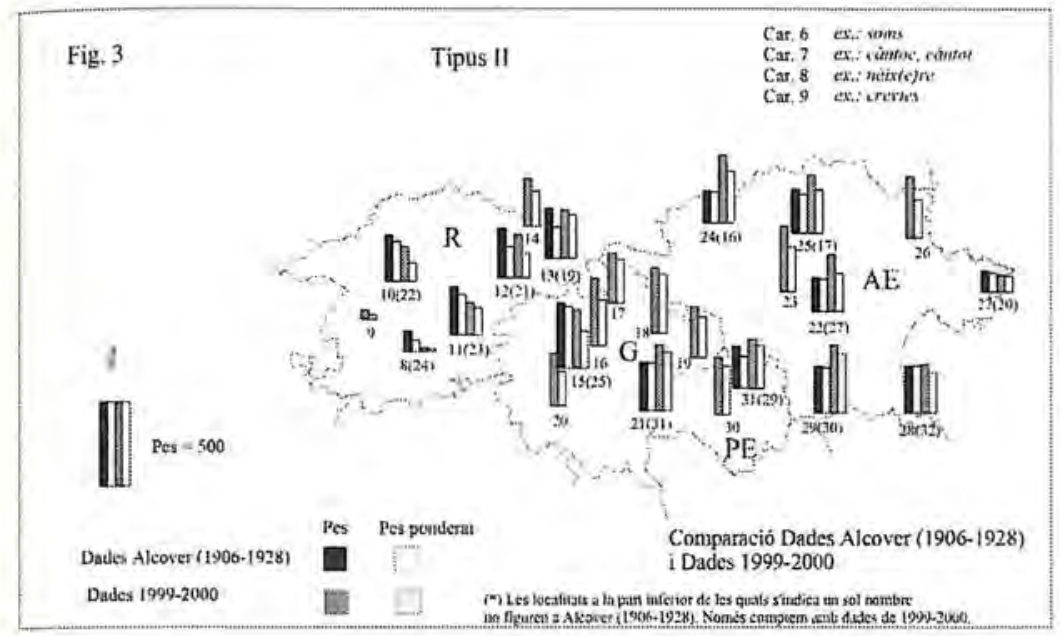

Fig. 4

4Pl: Verbs del subgrup [-w] de la subclasse verbal [II, * ext.]
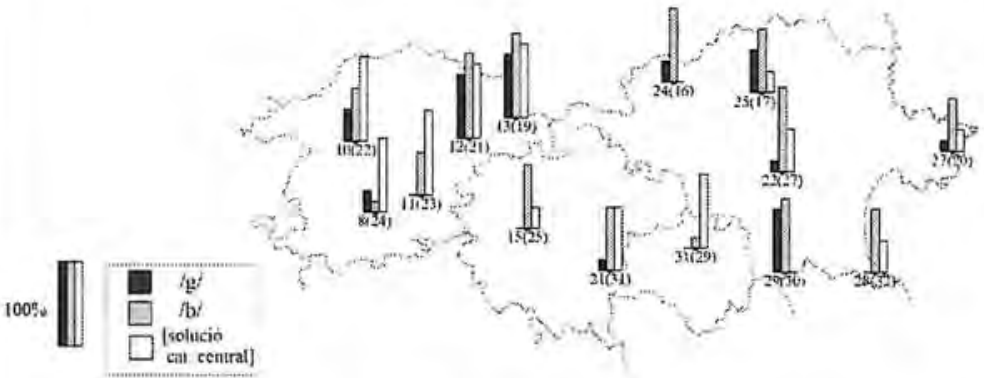

Verbs: cuurc, cloure, coure, sreare, jeure, plaure, nure, seure, treure

Dades Alcover 1906-1928 
Fig. 5

4 PI: Verbs del subgrup $[-w]$ de la subclasse verbal $[I I, \div$ ext. $]$

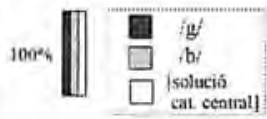

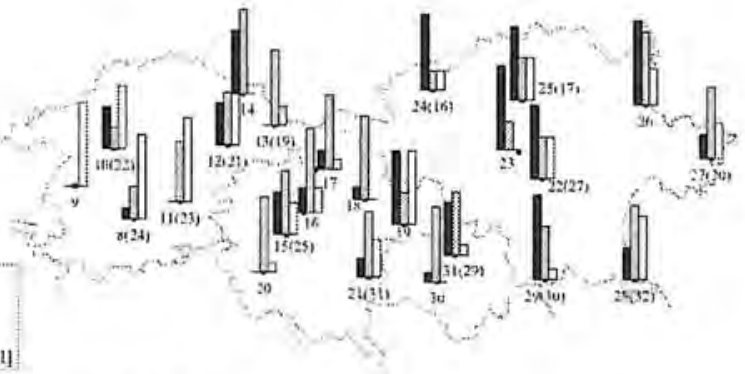

Verbs. caure, cloure, (com)piaure, coure, creure, jeure tiure, seure, treure

Dades 1999-2000

Fig. 6

Tipus 11

Car. 6 exis sitms

Car. 7 ex:. càntoc, caùthi

Car. 5 ex. neixfeje

Car. 9 exic weves

Car, 10 exis croguean

Pes $=500$

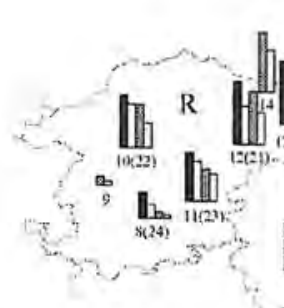

in 45

$\mathrm{PE}$

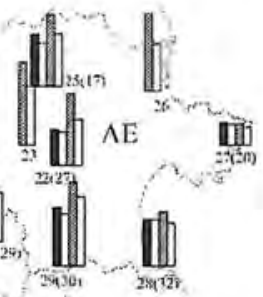

Pes Pes pondent

Dades Alcover (1906-1928)

Dades 1999-2000 
Y:Pes

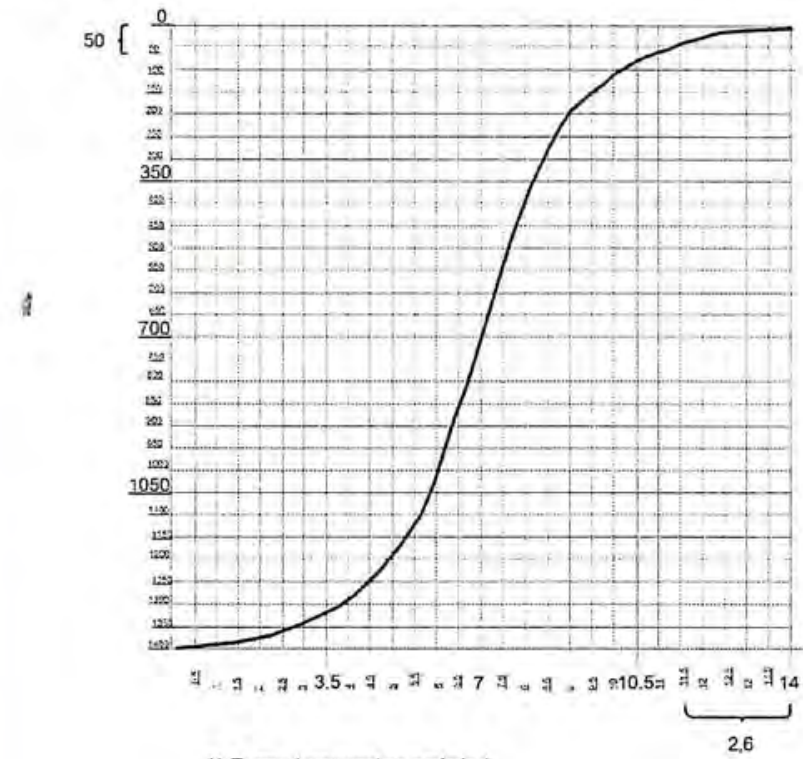

$X:$ Temps (expressat en periodes)

Fig. 7. Una aplicació de la corba-S del canvi lingüistic de Chen (1972)*

"Shi ategere, com a exemple, als resultals per a la car. 5 (ex. dir $\theta$ ), ta qual presenta una variactó do pes des dol valor do 50 dels inicís del s XX fins al 0 actual; if corresponen 2.6 periodes de corba recorreguts

Fig. 8. Tipologia espacial I (Des del punt de vista del nord del català central)
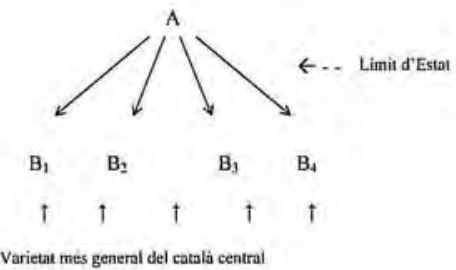

A: Grau màxim de realització $=$ rossellonès

$B_{1}, B_{2}, B_{3}, B_{4}:$ Grau de realítzació minim = nord del catala ceritral 
Fig. 9. Tipologia espacial II (nord-est del catalá central = bisbat de Girona)

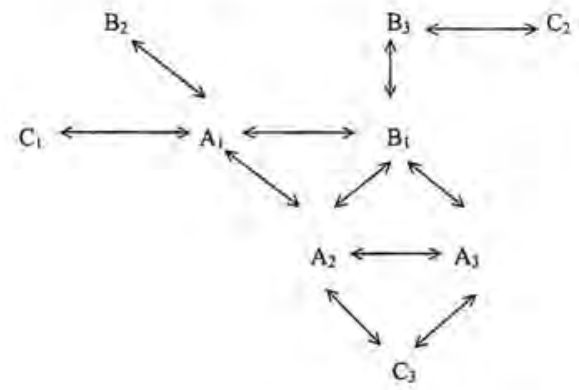

$$
\begin{array}{lllll}
\uparrow & \uparrow & \uparrow & \uparrow & \uparrow \\
& \text { Varjetat més general del català central }
\end{array}
$$

$\Lambda_{1}, \Lambda_{2}, \Lambda_{3}: G r a u$ màxim de realització $=$ en general, es tracta del centre de la zona.

$\mathrm{C}_{1}, \mathrm{C}_{2}, \mathrm{C}_{3}$ Grau minim de realització = en els punts en qué la zona entra en contacte més directe amb la varietat més general del català central (sud del Ripollés, alguns sectors de la Selva) o bé Cadaqués (que ocupa una posició aifllada) 